PART II.-REVIEWS.

The Senses and the Intellect. By Alexander Banv, M.A., Professor of Logic in the University of Aberdeen. (Second Edition.) London: Longman and Co., 1864, pp. 646.

That this work has arrived at a second edition is seemingly a favorable sign of the times, forasmuch as the fact may be assumed to indicate a general progress towards juster conceptions of the nature of mental phenomena and of the method to be followed in their investigation, than have commonly hitherto prevailed. Mr. Bain has been the first in England amongst the so-called mental philosophers to recognise the supreme importance of physiology as lying at the bottom of a true mental science; in other words, he has been the first architect in that department who has thought it necessary to look to his foundations. For a long time physiology has been steadily encroaching on territory which the metaphysical psychologist thought to be his own; and it now requires no great sagacity to see what the not distant end must be. After the psychological method has been in fashion for at least two thousand years, what is the result? Truly, a barrenness of result which its extremest advocate cannot well applaud, inasmuch as, to use Bacon's words, " not only what was asserted once is asserted still, but what was a question once is a question still ; and instead of being resolved by discussion, is only fixed and fed." It cannot, then, be accounted presumption if we refuse to believe that what has not been done by Plato and Descartes will be done by others following the same method. But it is reasonable to believe that what great men have not done may yet be done by inferior men adopting a method which they had not tried. At the present time it is simply an impertinence-etymologically speaking - in any one who has not made himself acquainted with the physiology of the nervous system to vex a heavy laden world with vague and vain psychological speculations; like the Aturian parrot of which Humboldt tells, * the metaphysical psychologist may almost be said to

* "There still lives, and it is a singular fact, an old parrot in Maypures, which cannut be understood, because, as the natives assert, it speaks the language of the Atures"-an extinct tribe of Indians, whose last refuge was the rocks of the cataracts of the Orinoco.- ' Views of Nature.'

"Wherefore your dabblers in metaphysics are the most dangerous creatures breathing; they have just abstraction enough to raise doubts that never would have entered into another's head, but not enough to resolve them."-Tucker's - Light of Nature Pursued.' 
speak in the language of an extinct tribe to a people which understand him not.

As the first genuine recognition, then, of physiology by an eminent psychologist, Mr. Bain's work has an importance apart from any question as to its execution. It cannot but be for the good of real science that one edition has been exhausted. Why it did not sooner get to its second edition, when the condition of thought was so favorable to the acceptance of a work of its kind, may perhaps be owing to these considerations : First, it is not physiological enough for the physiologist, who may naturally still prefer the concise, consistent, and suggestive account of mental phenomena which Müller has given in his excellent work on physiology. Secondly, it has been too physiological for the mere psychologist, who, preferring easy speculation to laborious acquisition and the conceit of dogmatising to the humility of learning, has been disgusted by matters which he knew nothing of, and which he was too indolent or too self-sufficient to study. Thirdly, it must be confessed that the descriptive character of the book, with its excess of elaboration and superfluity of detail, renders an excellent work somewhat tedious to the reader.

Mr. Bain's method.-As was well pointed out by Mr. Herbert Spencer, in a review of the 'Emotions and Will,'* the method which Mr. Bain adopts is such as must render his work essentially transitional, and, we may add, less interesting than it might easily be. He describes in great detail, with a superfluity of illustration, and not unfrequent iteration, the most manifest mental characters as they are tbserved subjectively and objectively, and takes little or no account of the genesis or development of mind as it is displayed in man or through the animal kingdom. Accordingly, we have a descriptive psychology which is scarce more lively than a school lesson in geography, and from which one would not easily learn that there was such a thing as an idiot in the universe, or that the infant's mind was a very different matter from that of the cultivated adult. Now there can be very little doubt that the study of the plan of development of mind is what is, especially wanted at the present time; and there can be even less doubt that such research, when rightly pursued, will do more than all that has yet been done towards establishing the principles of a science of mind. The only way of truly interpreting life in any of its forms is to investigate the plan of its development; and to give a laboured description of all its external features, without analytical insight into the mode of its being, will convey no more adequate an idea of it than one would get of a violet by buying from the chemist a dram of syrup of violets. We cannot, indeed, see how Mr. Bain reconciles his plan with the natural history method which he professes to follow ; for the position of any creature in the animal kingdom is not determined from superficial 
resemblances, but from the deeper identities of structure, as these are recognised by anatomical analysis and the study of development.

Without being guilty of extravagance, it may be held that a descriptive psychology never can be truly descriptive; for it must deal only with the surface of a fact, not with the fact itself. A fact never is a fact in science until its relations are discovered and its nature guaranteed. Before admitting a proclaimed fact, it is of essential importance to know something of the observer's previous education and training; otherwise one may not unlikely get about as correct an estimate of it as the ignorant peasant would give of the sun's diameter from his personal observation. Whosoever would truly realise this truth, let him analyse what are called the facts of consciousness. Sensation, for example, is generally used in works on psychology to denote a certain constant inborn faculty, instead of being understood as-what Berkeley's writings might have shown it to be-a general term summing up a multitude of particular phenomena of every degree of variation: the abstraction from the particular is converted into an objective entity which henceforth tyrannises over the thoughts. The sensation of each sense is in truth a gradually organised result or faculty which is built up through experience: the visual sensation of the cultivated adult is a very different matter from that of the child whose eyes have only been some weeks open upon the world; the tactile sensation of the blind man is a very different matter from that of the man who has always had the full use of his eyes; and the blind man whose sight was restored in the age of miracles saw men, not as men, but as trees walking. The complete sensation is slowly built up in the nervous centres from the residua or traces which previous sensations of a like kind have left behind them; and the sensation of the cultivated sense thus sums up, as it were, thousands of experiences, as one word often sums up the accumulated acquisitions of generations. Simple as a sensation appears, it is in reality infinitely compound. Of what permanent value, then, can any system of psy:chology be which takes no account of the gradual development of sensation as a process of organisation? Mr. Bain has analysed with great skill and completeness our perceptions of solidity, distance, figure, space, but he does not seem to have sufficiently recognised the important range of function of the sensorial ganglia as nervous centres with a power of independent action.

There can be no doubt that the large collection of carefully classified materials which Mr. Bain has made will be of the greatest value to some future architect whose good fortune it shall be to build up the fabric of a mental science. One can only regret that he himself should have wauted that organising faculty; for not only is he thereby prevented from raising the structure that shall endure, but his work, as far as it goes, suffers not a little. A striking feature, for example, in the book is the quantity of anatomical detail, and yet it might be 
truly said that the physiology and psychology are not really blended; but suggest the idea of being unwillingly chained to one another. While giving an adequate description of the structure of the nervous centres, Mr. Bain has, in fact, almost forgotten to give any account of their functions : the consequence is, that physiology avails him but little in his psychological disquisitions, and that throughout his book it rather suffers the torture of Mezentius, whereby the living are stifled in the embraces of the dead. Had the kind Destinies but thought well to roll into one philosopher Mr. Bain and Mr. Herbert Spencerwith true respect for such eminent men be it said - and how excellent would have been the result! They supplement one another so exactly that the writings of one are the best criticism on those of the other.

If it be said, in answer to the foregoing observations, that our knowledge is so incomplete and changing as to render it absurd to attempt any final result in mental science, the reply must be allowed to have great weight. For some time to come, undoubtedly, all works on mental science must be provisional; but there does not appear to be any wisdom in establishing provisional systems which are inconsistent with actually known facts, as the so-called empirical psychologists are continually doing. They claim for their science the character of being inductive, while they persistently ignore the instances in their simplest forms, and have recourse to the most complex. That is a fine sort of induction! Where have the idiot, the animal, and the infant their places in this inductive psychology? To speak of induction where such a number of important instances are neglected is an unjustifiable and mischievous misuse of the word. A psychology which is truly inductive, and therefore of permanent worth, must follow the order of nature, and begin where mind begins in the animal and infant, gradually rising to those higher and more complex phenomena of mind which the introspective philosopher discovers or thinks he discovers : the genesis, the progression, and the decay of mind as traceable in the animal or infant, the philosopher, and the maniac or idiot, should severally receive full consideration. "The truth is," as Bacon says, " that they are not the highest instances which give the best or securest information, as is expressed not inelegantly in the common story of the philosopher who, while he gazed upon the stars, fell into the water; for if he had looked down he might have seen the stars in the water, but looking aloft he could not see the water in the stars."

Certainly it may be said, and it is said, that conclusions as to the mental phenomena of the child can be correctly formed from the phenomena of the adult mind. But it is exactly because such inferences have been made that the mental phenomena of the child have been misunderstood and erroneously interpreted, and that psychology has not received the benefit of the corrections which a right interpretation of them would have supplied. It may be said again, and it is said, 
that the mental phenomena of the idiot or lnnatic are morbid, and do not therefore concern psychology. They certainly do not concern a psychology which violently separates itself from nature. But it is exactly because psychology has thus violently separated itself from nature-of which the so-called morbid phenomena are no less natural a part than are the phenomena of health-that it has not sure foundations; that it is not inductive; that it has not profited by the corrections which the faithful observation of the phenomena of the unsound mind would have afforded. In reality, insanity furnishes what in such matter ought to have been seized with the greatest eagerness-as they cannot be made-actual experiments for the establishment of true principles; and the only excuse the psychologists can have for ignoring them as they have done is that they would undoubtedly have rendered most of their works unnecessary, and have laid bare their ridiculous pretensions to science. The laws of action of the unsound mind are not different from those of the sound mind, only the conditions are changed : nature does not recognise the artificial and ill-starred divisions which men for their convenience make; and a mental science which shall truly reflect nature must embrace all mental phenomena. Meanwhile, such works as do not, even though elaborate and valuable as Mr. Bain's is, must be essentially transitional.

General plan of the book.-After a preliminary description of the nerves and nervous centres, it is divided into two principal parts :

I. The first division consists of four chapters, the first of which treats of Action and movement considered as spontaneous, together with the Feelings and impressions which result from muscular activity; the second is occupied with an elaborate account of the Senses and Sensations; the third deals with the Appetites, or the cravings produced by the recurring wants and necessities of our bodily or organic life, such as Sleep, Exercise, Repose, Thirst, Hunger, and Sex; the fourth chapter finally includes the Instincts or the untaught movements, and also the primitive rudiments of Emotion and Volition: only the rudiments of these last, be it observed, for the ' Emotions and the Will' are treated of fully in a separate book.

II. The second division of the book is occupied with an exposition of the Intellect, the three primary or fundamental attributes of which are described as (1) Consciousness of Difference, or Discrimination; (2) Consciousness of Agreement; and (3) Retentiveness-the commonly recognised intellectual faculties being resolvable, Mr. Bain holds, into those three primitive properties. The first two chapters of this second part are occupied with a full development of the two processes of Retentiveness and Agreement; a third chapter is devoted to cases of complicated mental reproduction, including association by contrast; and a fourth interesting chapter deals with the application 
of the intellectual forces in the formation of original constructionsthe so-called creative or inventive faculty of the mind.

As it would be absurd to attempt to criticise in detail so large and important a work, it must suffice here to fix arbitrarily upon certain points which seem to demand consideration, or which appear to be especially instructive. It would be quite easy to fill pages with valuable extracts, but as those who take a great interest in the progress of mental science have read or will read the book itself, nothing would be gained by such unnecessary mutilation.

The Brain as the Organ of the Mind.-While Mr. Bain holds it to be certainly proved that the brain is the principal organ of the mind, and that-though sensible of the value of quality - there is an indisputable connection between the size of the brain and the mental energy displayed by the individual man or animal, he appears to be somewhat troubled by the unfortunate fact that the connection of force of mind with richness of convolutions is liable to exceptions : the sheep's brain, for example, is more highly convoluted than that of the dog, the donkey's brain more highly convoluted than that of the beaver. As the popular views on this subject are not very exact, we take leave to add a few observations.

As a general proposition, it is rightly held that the size of the brain in man is in proportion to the intelligence; but in judging of the relation in any case, it is obviously of great consequence to discriminate the kind of intelligence: there is all the difference in the world between the man of genius who is possessed of the creative faculty and marks out new paths, and the man of industrious talent who plods on with intelligent success in the old paths. For some time, again, it was believed that man had absolutely the greatest brain weight amongst animals; but though the proposition was true of most animals, it was found not to be true of the elephant and whale, neither of which of course approach man in intelligence. Then, it was said that if man had not the heaviest brain absolutely, his brain was still the heaviest in relation to the weight of his body-a relation which is in him as 1 to 36 , whilst amongst most intelligent animals it seldom exceeds 1 to 100 . Some of the smaller creatures, however, upset that proposition; the smaller singing birds, for example, exhibit variations in the relative proportions which exceed the normal proportion in man; and even the small American apes ure said to have a proportionately greater weight of brain than man.

It is not absolutely true, again, that one animal is more intelligent than another as the convolutions of its brain are more numerous and the sulci deeper. Certainly, there gre no convolutions in the lower mammalia, whilst they are met with in the carnivora and the apes with very few exceptions. The development of the convolutions in those animals which do possess them appears, on closer examination, to be in some degree in relation to the size of the body. 
Not that all large animals are more intelligent than the smaller ones; for the brains of the ass, the sheep, and the ox are more convoluted than those of the beaver, the cat, and the dog. But a mathematical consideration comes into play here : when two bodies of like form but different size are compared, their relative volumes are as the cubes of their diameters, while the superficies of them is related as the squares of the diameter; or, in other words, the volume of a body which increases in size, increases in greater proportion than the superficies, and the latter again in greater proportion than the diameters. Now, in every natural group or order of mammalia the head, but specially the capacity of the skull, has a certain relation to the body which remains nearly equal in different species : the head of the tiger or the lion has the same proportion to the body as the head of the cat has to its body, although the sizes of the animals are so different. The relative proportion of the brain to the body in the tiger being, then, equal to the proportion in the cat, the superticies of the skull cavity will be proportionately smaller in the larger animal ; and, consequently, to obtain an equal development of the gray superficies, this must be convoluted in the larger animal, while it may remain smooth in the smaller one. Plainly, then, this is an important consideration to be borne in mind in examining the fashioning of the convolutions in relation to the development of intelligence iu different animals. Comparisons on such matters can only be rightly made between members of the nearest allied groups.

Of man, it may be added that not only is his skull more capacious in proportion to the size of his body than that of the larger animals, but that he far surpasses all other animals in the number and variety of his convolutions. And there can be no doubt that the complexity of his convolutions is in relation to the superiority of his intelligence. That wherein the monkey's brain differs from his-viz., the greater simplicity of the convolutions and their more symmetrical character -is that in which, in less degree, the brain of the lowest savage differs from the brain of the average European; the lowest savage undoubtedly occupies, as regards the conformation of his brain, an intermediate position between the European and the ape, though of course he is very much nearer to the European than he is to the ape.

The remarks which follow will serve to show how little liable Mr. Bain is to any charge of dealing with mental phenomena in the metaphysical spirit, and are not without interest as coming from a Professor in a Scotch University :-

"It is now an admitted doctrine that the nervous power is generated from the action of the nutriment supplied to the body, and is therefore of the class of furces having a common origin, and capable of being naturally converted-including meclunical momentum, heat, electricity, magnetism, and chemical decomposition. 'The power that animates the human frame and keeps alive the currents of the brain has its origin in the grand primal 
source of reviving power, the sun; bis influence exerted on vegetation builds up the structures whose destruction and decay within the animul system give forth all the energy concerned in maintaining the animal processes. What is called vitality is not a peculiar force, but a collocation of the forces of inorganic matter in such a way as to keep up a living structure. If our means of observation and measurement were perfect, we might render an account of all the nutriment consumed in any animal or human being; we might calculate the entire amount of energy evolved in the changes that constitute this consumption, and allow one portion for animal heat, another for the processes of secretion, a third for the action of the heart, lungs, and intestines, a fourth for the muscular exertion made within the period, a fifth for the activity of the brain, and so on till we had a strict balancing of receipt and expenditure. The evidence that establishes the common basis of mechanical and chemical force, heat and electricity, namely, their mutual convertibility and common origin, establishes the nerve force as a member of the same group."

Reflex action.-It has been already said that Mr. Bain's ideas of the functions of the different nervous centres do not seem to represent adequately the present state of knowledge; in fact, he mostly confounds their independent and special actions under the one general name of mental action. The consequence is, that actions in which the mind, as usually understood, has no part are by him endued with consciousness, and a want of exactness vitiates much of what he says. One of the results of the removal of the cerebral hemispheres he describes to be the entire extinction of all power of moving for an end; and yet he is immediately afterwards driven to acknowledge with surprise "an extraordinary apparent exception" to this conclusion in a well-known experiment by Pflüger. That physiologist wetted with acetic acid the thigh of a decapitated frog over its internal condyle, and the animal wiped it off with the dorsal surface of the foot of the same side; he thereupon cut off the foot and applied the acid to the same spot, and the animal-deceived, seemingly, as the man who has lost a limb is, by the eccentric sensation-would have wiped it off again with the foot of that side. But after some necessarily fruitless efforts it ceased to try in that way, seemed unquiet " as though it were searching for some new means," and at last it either made use of the foot of the other leg, or it so bent the mutilated limb that it wiped it against the side of its body. Struck by this wonderful adaptation of movements to an end by a headless animal, Pflüger actually inferred that the spinal cord, like the brain, was possessed of sensorial functions. And Mr. Bain appears to be of much the same opinion, for he says - "These actions have the character of voluntary actions, and yet they proceed from no higher centre than the spinal cord. We have no means of adequately explaining such a phenomenon. Possibly, in animals of a low order, the processes of will and intelligence are not so exclusively centralised in the brain as in the higher vertebrata." It would be rather interesting if Mr. Bain, in his next edition, would give a chapter on the processes of 
will and intelligence in animals of so low an order as the frog; we fear that it would very much resemble the celebrated chapter ' $C$ oncerning Snakes in Iceland.'

Let us consider for a moment Pflüger's experiment. Is it not quite possible to draw another inference from it than that which he drew? Assuredly it is : the so-called design of an act is not necessarily evidence of the existence of will, forethought, or even consciousness. That would seem to be a far juster inference. No doubt there appears to be purpose in the movements of the decapitated frog, as there is purpose in the movements of the anencephalic infant's lips; but in both instances the co-ordinate activity is the result of a prearranged endowment of the nervous organisation. Accordingly, we see that the frog which has lost its leg acts as if its foot were still there, which, had it consciousness, it plainly should not, and only employs other means when the irritating action of the stimulus continues unaffected by its efforts. As, in certain morbid states of the human organism, we observe that the continuance of an irritation which at first only causes slight reflex action may produce more general involuntary reaction or convulsions; so, in the frog, the enduring stimulus which has not been affected by the customary reflex movements, gives rise to those further co-ordinate reflex movements which would have now come into play had the frog still possessed its brain. In the constitution of the spinal cord are implanted the capabilities of such energies, and the degree of the necessity, or the intensity of the stimulus, determines the extent of the activity. But the movements take place without consciousness; and all the design which there is in them is of the same kind as the design which there is in the formation of a crystal, or in the plan of growth of a tree. A crystal cannot overstep the laws of its form, nor can a tree grow up into heaven; the particles of the crystal aggregate after a certain definite plan, and thus strictly manifest design. Are we then to assume that because of the design there is consciousness in the forming crystal or in the growing tree? Certainly not; and yet it is to that absurd conclusion that the arguments of those who look upon the so-called design of an act as evincing consciousness must lead. The design evident in any act is nothing else but the correlate in the mind of the observer of the law of the matter in nature; and each observer will see in any act just that amount of design which he brings with him the faculty of seeing.

Let it be remembered that reflex co-ordinate movements may not only take place as the result of an innate endowment of the spinal cord, which is commonly the case in the lower animals, but that the faculty of such movements is an acquired faculty of the cord in many of the higher animals and in man-an organised result in the spinal centres built up through particular experience and training. Pathological records will furnish many instances in which movements having 
the appearance of design are notably accomplished by man when the influence of the cerebral hemispheres is suspended and consciousness absent. When Coleridge, in one of his letters to Godwin, asks " whether there be reason to hold that actions bearing the semblance of predesigning consciousness may yet be simply organic, and whether a series of such actions are possible," he was uncertain about that which some of his great predecessors had very distinctly and very justly perceived, and which, if he had forgotten Hartley, a glance at the physiology of his time might have easily decided. Not to instance the mechanical automata which Descartes makes of the animals, Spinoza had put the matter in no uncertain manner. "No one," he says, "has in fact yet determined what the body is capable of; in other words, no one has learned from experience what the body can do and what it cannot do by the mere laws of its corporeal nature, without receiving any determination from the mind." And after saying that no one has sufficiently studied the functions of the body, and instancing the marvellous acts of animals and of somnambulists-" all things which prove that the human body, by the mere laws of its nature, is capable of a multitude of acts which are astonishing to the mind" - he concludes, "I add, in conclusion, that the mechanism of the human body is constructed with an art which infinitely surpasses human industry." The attentive study of the development of the functions of the spinal cord does indeed appear to us to be an essential prerequisite to the formation of just conceptions of the large part which it undoubtedly plays in the phenomena of our mental life.

Sensori-motor action.-After what has been said, it will not be surprising that Mr. Bain rejects sensori-motor actions as a class apart from others, believing that Dr. Carpenter, with whom he was at one time disposed to agree, has laid hold under that division of a number of movements due to the diffusive influence of feelingan influence upon which Mr. Bain insists much.* It would be very desirable that any one who is about to quote Dr. Carpenter on any subject should try to get back to the original source from which that eminent and useful compilator has gathered his materials. Certainly it is not very probable that he will find the references where they might be expected to be, but he must be none the less

* The way in which Mr. Bain speaks of this diffusion of emotion, as if it were something hitherto almost entirely neglected, is rather surprising. In reality it has been over and over again dwelt upon with much greater exactness than by Mr. Bain. Bichat ('Sur la Vie et la Mort') located the passions in the organs of organic life, so much was he impressed by it; Henle described the emotions as sympathies between the organ of thought and the bodily nerves (" Ration. Pathologie,' vol. i, 1846); Domrich treats in detail of the influence of the feelings not only on motor nerves, but on the different organs and upon nutrition ( Die Psy. chischen Zustände, ihre organische Vermittlung,' \&c., 1849); and Wachsmuth ("Allgemeine Puthologie der Seele), is sufficiently distinct upon the subject; as most German manuals of psychology are. 
sure on that account that there are such. With regard to this question of the sensori-motor actions, which Dr. Carpenter has done so much to illustrate, the criticism of Mr. Bain is in some degree valid; but it is so only in so far as Dr. Carpenter has confused, by doubtful instances, a well-defined class of movements. Perhaps the most lucid and philosophical account of sensations as independent causes of movement will still be found in a paper by Griesinger, published in 1843. It is entitled, "On Psychical Reflex Action," and it is specially devoted to displaying a parallel between the actions of the brain and the spinal cord. Mr. Bain's doubt of the existence of such a class of moveinents must seem to the physiologist inexplicable. Not only physiological and pathological observation, but experiments on animals and anatomical researches, have agreed in proving both the possibility and the actuality of the movements; and have proved also that they are by no means insignificant in the daily actions of life. Unwarrantably to suppose, as Mr. Bain does, that the cerebral hemispheres are essential to the manifestation of sensori-motor actions, only shows how dangerous it is to give an opinion upon a physiological question on psychological grounds, or on the basis of unassimilated extracts from physiological text-books. It is an error from which a consideration of the place of development of mind would have haply saved him; for it is the simple fact that in a great number of the lower animals, in which there are no cerebral hemispheres, the actions are entirely reflex and sensori-motor. It is not, indeed, till we get near to the lowest forms of the vertebrata that any higher form of mental action is manifest.

Movement precedes sensation, and is at the outset independent of any stimulus from without.-This is a matter upon which Mr. Bain lays the utmost stress, returning to it again and again with an iteration which, though it may be impressive, certainly becomes rather irritating. As he points out, the original spontaneity of movement was taught by Müller, who maintained that the foetus moves its limbs at first, not for the attainment of any object, but solely because it can move them. The mistake of Müller, which was a very natural one at the time, was, that he called this spontaneity voluntary; which Mr. Bain, notwithstanding that he himself can find processes of intelligence and will in the frog, asserts very properly that it is not. But has Mr. Bain altogether avoided confusion on this matter? One thing has forcibly struck us in his disquisition; it is, that he has confounded, or certainly not sufficiently discriminated, a stimulus and a sensation. It is obviously quite possible - and, indeed, it is not denied - that movement may, and does, precede sensation; but it does not thereupon follow that it is independent of a stimulus from without. The reflex movement is independent of consciousness, but it is not independent of the 
stimulus from without. Whether the first movement of the fœtus takes place on the occasion of some external stimulus, or whether it is a spontaneous outburst of energy, in either case there is the best reason to believe that it is unattended with sensation. If all that Mr. Bain means to say is, that movement precedes sensation, he only says what, as far as we know, no one denies. But if he wishes to uphold that movement takes place independently of a stimulus, then it is necessary to come to some agreement as to what a stimulus shall mean.

Physiologists are in the habit of describing a class of stimuli as the organic stimuli, and of laying the greatest stress upon the important influence which these conditions arising within the body exercise upon the tone of the nervous centres. Ordinarily their agency is exerted upon our unconscious mental life-a life of which we observe, not without amazement, that Mr. Bain takes no account in his book; but in the abnormal case of a disturbance in some of the organs of the body, an influence usually exercised without consciousness forces itself into consciousness, and produces easily recognisable effects. The plenomena of insanity, and the disorders of motility, furnish many instructive examples of such action. Now, as it would of course be impossible to say that movement is independent of a stimulus, if the organic stimuli were admitted, Mr. Bain sweeps them away from the field, scarce deigning them a moment's consideration. "A constant stimulus," he says, " is in our estimation no stimulus at all." Very well : but, pray, let us have some consistency. If a constant stimulus is no stinulus at all, what does Mr. Bain mean by talking, as he does very fluently and very hypothetically, of the tonicity of certain muscles being kept up by a stimulus originating in a nervous centre, and constantly flowing out from that centre-an assumption, be it observed, out of which he fashions an argument in favour of the spontaneity of movements. In this regard he has plainly not been sufficiently careful and exact. Moreover, if it be true that a constant stimulus is no stimulus at all, the admission does not settle the matter; for the organic stimuli are not constant, but vary with every variation in the condition of the organs-variations to which the complex and delicate machinery of the organism is exceeding sensitive. A movement then may be excited, not only directly by a stimulus from without, but also indirectly through the obscure effects produced by the external stimulus upon the organic stimuli. And as the infant, when it gets into the world, is surrounded with a universe of external stimuli; and as its organic stimuli at once come into play with the commencement of life on its own account, we must confess that Mr. Bain's undiscriminating proposition hardly seems to do justice to the difficulties of the qucstion.

We do not say that Mr. Bain is wrong; on the contrary, we 
are of opinion that his arguments for the spontaneity of movementswhen the term is properly defined - are of great weight, and might have received stronger illustration; but we certainly think that he has exaggerated the value of his own rather vague and general proposition, and has very much underrated the more exact knowledge which was in existence. When he goes on, for example, to argue that the nervous centres do not merely reflect the stimulus of the afferent on to the efferent nerve-that the reflex movement is not the pure creation of an outward stimulus, but is determined partly by the stimulus and partly by the specific force of the centres-he is simply stating one of the most elementary propositions in physiology, and, in so far as he is fighting, is fighting with an imaginary enemy; the principle is at the foundation of that discrimination of nervous centres which physiologists have long made, but which Mr. Bain unfortunately does not make. Did any mortal ever think when he touched his horse with the whip or the spur that the consequent activity merely represented the transferred stimulus? When, again, he cites the phenomena of awakening from sleep to prove that movement precedes sensation, he appears to be all unaware of the possibility that the senses may be awake while the cerebral hemispheres are asleep, as the cerebral hemispheres may be active while the senses are asleep. On the whole, it must be said that his physiological knowledge is wanting in exactness and completeness, and by no means reaches the level of the present condition of the science.

That acknowledgment made, however, we would again direct attention to his valuable observations upon the spontaneous energy which is stored up in the nervous centres by nutrition, and discharged, whether on the occasion of some external stimulus or not. Of especial value is his exposition of the primitive combined movements as original and instinctive in man as well as in the animals; the associating link existing in the original conformation of the nervous centres. This pre-established adaptation for locomotive movements involves, as he points out, first, the reciprocation or vibration of the limb, which certainly is not due to volition; and, secondly, an alternate movement of corresponding limbs, or of the two sides of the body. In animals, whose particular ways of walking are transferred as an inheritance of structure, the primitive adjustment is more evident; and in man there is, as Müller observes, an example in the movements of the two eyes together of associated simultaneous movements depending on the structure of the nervous centres. Is it not strange, however, that Mr. Bain, insisting so much upon this primitive germ of a locomotive harmony, should have thought it essential in an earlier part of his book to associate processes of will and intelligence with co-ordinate movements? Per- 
haps we should nqt be far wrong in saying that there is a mechanical conformation rather than an organic unity apparent in his work; that the structure seems complete, but life is wanting.

Muscular feelings.-By no one in England has the analysis of onr muscular perceptions been so thoroughly done as by Mr. Bain. He distinguishes three distinct classes of muscular feelings :-

1. Feelings connected with the organic conditions of muscles, as those arising from injuries, disease, fatigue.

2. Feelings connected with muscular action, including all the pleasures and pains of exercise.

3. The feelings which indicate the various modes of tension of the moving organs. These are the feelings which enter largely into our intellectual life, and play a most important part in thought. This function of muscular sensibility arises from our being conscious of the different degrees of tension; and the modes of muscular action which thus affect us Mr. Bain holds to be three:-(a) The first is the amount of exertion which measures the resistance to be encountered; and under this category comes the discrimination of weight, of tenacity, of elasticity, \&c. It is the feeling and measure of resistance or force-the feeling that is the principal foundation of our notions of an external world. (b) The second has regard to the continuance of the exertion, and applies both to dead strain and to movement. It stands for a measure of time. " All impressions made on the mind, whether those of muscular energy or those of the ordinary senses, are felt differently according as they endure for a longer or a shorter time. This must be true of the higher emotions also. The continuance of a mental state must be discriminated by us from the very dawn of consciousness, and hence our estimate of time is one of the earliest of our mental aptitudes. It attaches to every feeling that we possess, although we do not always exercise the power of making this special comparison and commit mistakes in consequence. When we pull an oar or raise a weight, we know that we are moring and not simply resisting; there is the sweep of the organ through space, and the range of muscular contraction thus connects itself with the measure of space or extension." Not very distinctly at all times, as Mr. Bain must allow, if he has ever pulled very hard against tide, and, notwithstanding the sweep of the organ through space, made little or no progress. "This is the first step, the elementary sensibility in our knowledge of space. And although we must combine sensations of the senses with sweep of movement in our perception of the extended, yet the essential part of the cognition is due to the feeling of movement." The sensibility becomes the means of imparting to us the feelings of linear extension, inasmuch as that is measured by the sweep of the limb; and of course discrimination of length in one direction includes extension in every direction. "Hence superficial and solid dimensions, 
the size or magnitude of a solid object, come to be felt through the same fundamental sensibility to expended muscular force." (c) The third form of muscular feeling is connected with the rapidity of the muscle's contraction to which the velocity of movement corresponds. For when we accelerate a movement we are aware, not merely that more power is going out of us, but we have a feeling of the rapidity of the muscular contraction, which is thence transferred to the moving object, so that the velocity of motion is estimated. "The feeling of the rapidity of muscular contraction has a further office. It is an additional means of measuring extension. An increase of velocity in the same time corresponds to an increase of range or extension, no less than the same velocity continued for a greater time. Extent of space thus connects itself with two separate discriminations-continuance, and velocity of movement."

It is plain, however, that the sense of touch co-operates largely with our muscular feelings in the formation of our notions of extension and solidity. Movement only would not give that distinction between succession and co-existence-time and space-which must be arrived at before we recognise extension. "When with the hand we grasp something moving, and move it, we have a sensation of one unchanged contact and pressure, and the sensation is embedded in a movement. This is one experience. When we move the hand over a fixed surface we have, with the feelings of movement, a succession of feelings of touch; if the surface is a variable one, the sensations are constantly changing, so that we can be under no mistake as to our passing through a series of tactile impressions. This is another experience, and differs from the first, not in the sense of power, but in the tactile accompaniment. The difference, however, is of vital importance. In the one case we have an object moving and measuring time or continuance; in the other case we have coexistence in space. The coexistence is still further made apparent by our reversing the movement, and thereby encountering the tactile series in the reverse order."

The perception of solidity is a complex result obtained through the union of touch and muscularity; and distance, direction, and situation involve in the same manner the active organs; "the tactile sensations merely furnishing marks and starting-points like the arrows between the chain lengths in land measuring."

"The observations made on persons born blind have furnished a means of judging how far touch can substitute sight, both in mechanical and intellectual operations. These observations have shown that there is nothing essential to the highest intellectual processes of science and thought that may not be attained in the absence of sight. The integrity of the moving apparatus of the frame renders it possible to acquire the fundamental notions of space, magnitude, figure, force, and movement, and through these to com- 
prehend the great leading facts of creation as taught in mathematical, mechanical, or physical science."

Theory of Vision.-In a recently published book an energetic attempt has been made by $\mathrm{Mr}$. Abbott to overthrow what is called the "Berkleian Theory of Vision," which, being the theory commonly accepted, renders it necessary for its opponent to encounter both Mr. J. S. Mill and Mr. Bain. To us it appears that Mr. Abbott has not adequately interpreted Berkeley, or certainly has not criticised him in a sufficiently wide and liberal spirit; and that in his somewhat confident energy he triumphs, not over rual adversaries, but over adversaries whom he has himself in great part created. At the present time it is probable that Berkeley's writings, honestly studied, would be very serviceable in illustrating how gradually our sensations are built up from the aggregate or residua of past impressions of a like kind - a fact which, in the case of vision, the stereoscope has experimentally demonstrated. Be that as it may, however, we do not find in the book of Mr. Bain those one-sided and incomplete opinions in regard to vision which Mr. Abbott quotes and exerts himself to overthrow. Let us exhibit this in greater detail..

The sensations, or the proper elements of sight, are, Mr. Bain holds, partly optical, resulting from the effect of light on the retina; and partly muscular, arising through the action of the six muscles of the eye. The complex sensations are formed from this combination, which, as in the case of touch, is necessary as a basis of our perception of the external world - externality, motion, form, distance, size, solidity, and relative position. Mere light and colour will not suffice to found these perceptions upon. The eye follows a moving object, and through the muscles acting we get a discrimination of direction, as also of continuance of movement, while the velocity causes graduated sensations of speed. "The muscular sensibility of the dead strain, or of resistance, can scarcely occur in the eye, there being nothing to resist its movements but its own inertia. Hence, of the three primary sensibilities of muscle-resistance, continuance, and speed-two only belong to the ocular muscles. Accordingly, the eye, with all its superiority in giving the mind the pictorial array of the external world, cannot be said to include the fundamental consciousness of the object universe, the sense of resistance. There is a certain kindred susceptibility in the common fact of muscular tension; but it is by association, and not by intrinsic susceptibility, that the power of vision impresses us so strongly with the feeling of the object world." This is distinct enough : Mr. Bain holds that by the eye alone we never could attain to the perception of things external to us, to the recognition of an external world. 
How do we get our perception of distance? There is a double adaptation of the eye to distance, namely, a change in the convexity of the lens for near distance, and an alteration in the direction of the axes of the eyes for distance both near and far; and as these adaptations are muscular, the corresponding muscular feelings give us our discriminating consciousness. "The recognition of difference of remoteness from the eye, in so far as can be done by vision alone, is the fusing of definite changes of adjustment with a definite series of optical impressions; the series being inverted by an inverted adjustment, and being repeated in the same order any number of times. With the near adjustment one class of objects are imaged distinctly to the mind; with an altered adjustment these objects, though still in view, fade into a characteristic indistinctness, and a new portion of the sphere attains the clearness of outline that the others formerly had. With another adjustment the same optical change is repeated, and so on till the eyes have gone through the entire compass of accommodation to distance."

By combining the impressions of varying distances with the sweep of the eye over the object or the field of vier, it is possible to conceive how we get visible pictures of the three dimensions of space, or recognise objects in their solid forms; for by a series of appropriate movements of the eyes we follow the outline of an object, obtaining thus certain optical effects in association with muscular feelings. "The union of those that are characteristic of each object is our permanent impression of that object, and is our means of recognising it in after times."

Such are Mr. Bain's opinions respecting our perceptions of distance and solidity, as they are expressed in one part of his book; but in another part of it he maintains that distance and the dimensions of a body in space cannot be perceived through the medium of sight alone. The meaning of distance, he there says, implies that it would take a certain number of paces to get to the object-a certain locomotion, in fact, measured by the putting forth and continuance of a certain muscular energy. "I say, therefore, that distance cannot be perceived by the eye; because the idea of distance, by its very nature, implies feelings and measurements out of the eye, and located in other active organs." This assertion, which is scarcely consistent with what has been previously said, represents a very dangerous style of argument, or rather it represents no argument at all. To say that the idea of a thing implies such and such consequence is simply to re-assert the same proposition in other and more objectionable words. The distance of an object in yards or feet may be a matter of locomotive determination; but it scarcely thence follows that we have no perception of externality and distance by the eye. What is the cause that immediately 
determines the adjustment of the eye to distance? Certainly the adjustment is not a locomotive acquisition : it is a conseusual, or, if you prefer the vaguer word, an instinctive act, in respondence to a visual sensation or picture-an act of which there is no direct consciousness, and over which the will has no direct control. Let this question, then, be put: If the sense of muscular energy is the basis of the idea of an external world, and the sense of its con. tinuance is the basis of the notion of distance, as Mr. Bain maintains, why should not the muscular feeling of the consensual muscular contraction in the unconscious adjustment of the eye be also the hasis of the idea of the external object, and the feeling of the continuance of the consensual act also be the basis of a notion of distance? The feeling of expended energy must surely impart a discrimination in the case of one muscle just as much as in the case of another-nay, even more distinctly in the case of the exceedingly susceptible muscles of the eye. But, says Mr. Bain, the eye cannot give you the feeling of resistance. What? Is the feeling of resistance, in any case, anything more than the feeling of expended muscular energy? In the case of any acting limb, is not the feeling an internal fact? How, then, do you get the notion of the external object? And if in such instance you do contrive, in some inexplicable way, to get such notion from a feeling which is purely internal, why may not a similar feeling in the eye give you a similar result? Nay, is it not far more likely to do so, seeing that in the eye a visual picture, which itself determines the muscular act, is constantly associated with the corresponding muscular feeling? No doubt the association of locomotive efforts with certain feelings in the eye is the rule, and the notion of distance is a compound result; but that the eye alone cannot impart such notion is certainly an assertion which will not easily be proved, and which Mr. Bain has not proved.

There is a distinction to be borne in mind in discussing this question, which, if we remember rightly, Mr. Abbott neglects. To say that the visual sensation may give us the perception of externality and distance is obviously a very different thing from saying the eye may give us such perception. It is not the visual sensation as such-not the eye as receiving the visual picture-which directly gives us the perception of distance; but it is the muscular feeling of adjustment which imparts the discrimination, just as the muscular feelings of our limbs do. In both cases in man the sensation is at first confused and uncertain, and the respondent muscular adaptations are gradually effected so that definite muscular intuitions are organised; and in both cases in some of the lower animals the muscular intuition is distinct and complete from the first. Certainly we may well entertain great doubts whether the vor. $\mathbf{x}$. 
Rovionos.

visual sensation itself would ever give us the notion of extarnality and distance.*

II. The Intellect.-It is a matter of unavoidable regret that we cannot afford to give an account of the second division of Mr. Bain's valuable work. It must suffice to say that he resolves all the commonly recognised intellectual faculties into three primitive properties-Discrimination, Retentiveness, Similarity. Memory is founded on the retentive power, aided sometimes by Similarity; Reason and Abstraction involve Similarity chiefly, there being in both the identification of resembling things; Judgment may consist in Discrimination on the one hand, or in the sense of Agreement on the other; and Imagination is a product of all the three fundamentals of our intelligence, with the addition of an element of Emotion. All this is fully and oystematically set forth in the chapters of the second part of the book. To us it would have been far more satisfactory if for the words Discrimination, Similarity, and Retentiveness Mr. Bain had substituted the physiological ideas of Assimilation and Differentiation, or the general idea of Organisation. What he has said would have lost nothing thereby, and his book would have gained something in unity. Moreover, we do not find in his proposed terms any important advance on those which were previously in use: Discrimination seems to be very much what is commonly called Perception or Discernment; Conception would embrace most of what he includes under that "vile phrase" Similarity; and if one must hold to psychological nomenclature, there does not seem to be any very cogent reason for putting Retentiveness in the place of the ancient and familiar Memory. To change old terms for new, when there is no actual increase in our knowledge of the facts denoted, and when we gain little or nothing in exactness thereby, is rather a questionable advantage.

Thus much, then, in the way of criticism of a valuable work, which is very carefully executed and full of information. With less labour rio might have selected as extracts many excellent observations by Mr. Bain, and have followed these up with the usual unintelligent approbation of the professional writers : had the book been an indifferent production, that is the way we should have depreciated it; but as it is not an indifferent book, it seemed more fitting to give it the appreciation of a discriminating criticism. Perhaps it may appear to

- Since the abore was written wo have met with a little work by C. S. Cornelius, ("Zur Theorio des Sehens mit Rticksicht anf die neuesten Arbeiten in diesem Gebiete,' Halle, 1864,) which contains a complete summary of all the argamente in favour of the muscular censations of the eje as the important agents in virion. $\Delta$ larger work by the same anthor is "Theorie des Sehens und ranmlichen Vorstellens,' 1861. It appears that the influence of the museular sensations was set forth by Steinbuch as early as 1811 ; first applied in a comprehensive theory by Herbart and his school; is expounded in detail by Cornelius, and supported by Iotze and Wundt. Waits, however, hold that the sensations of colour muy, without auy co-operation of muscular feeling, lead to the conception of extension in space. 
some that, seduced by the critical spirit, we have been too much occupied in fault-finding; if so, let such read the book and get a correct notion of its value for themselves. Others may think that we might have done well to make larger quotations; if so, let them accept an excuse in Milton's words : "Others may read him in his own phrase and ease me, who never could delight in long citations, much less in whole traductions; whether it be natural disposition or education in me, or that my mother bore me a speaker of what God made mine own, and not a translator." ('Doct. and Discip. of Divorce.')

\section{H. M.}

Crania Britannica. Delineations and Descriptions of the Skulls of the Aboriginal and Early Inhabitants of the British Islands, together with Notices of their other Remains. By J. BARNARD Davis, M.D., F.S.A., \&c.; and JoHN ThURnaM, M.D., F.R.C.P., F.S.A., \&c. Decade V. London, 1862.

THOogr late with our notice of this most valuable and original work (inasmuch as it has reached the fifth section or "decade" of six which will complete it), yet we should neglect a positive duty did we let those of our readers, who have not yet met with it, continue ignorant of the character and merits of its contents, particularly as one of its authors is a member of the Association, and the muchesteemed Superintendent of the Wilts County Asylum.

The study of the human cranium as the enclosing and protecting envelope of the brain-the organ of the mind-and intimately correlated with the brain in structure and development, is necessarily a favorite one with those who make mental medicine the special object of attention. That such is the case is evidenced sufficiently by the comparatively large number of names of medical officers connected with our English asylums found in the list of subscribers to this work. For we should have noted that it is published by subscription by Taylor and Francis, Red Lion Court, Fleet Street.

Dr. Thurnam is united in the production of this laborious treatise with Dr. J. Barnard Davis, of Stoke-on-Trent, a gentleman who, amidst the arduous duties of general practice, has found leisure to prosecute craniological researches most thoroughly, and to form the. finest collection of skulls to be met with in Europe.

Such works reflect credit, not only on their authors, but also on their native country. The original conception of the work appears to have been borrowed from Prof. Morton's celebrated 'Crauia Americana.' It does not consist in dry, anatomical details of structure, but the study of the crania is used to, as it were, resuscitate the races to which they belonged, and to bring before us the 
The Senses and the Intellect: By Alexander Bain, M.A., Professor of Logic in the University of Aberdeen. (Second Edition.) London:

Longman and Co., 1864, pp. 646

H. M.

BJP 1865, 10:550-569.

Access the most recent version at DOI: 10.1192/bjp.10.52.550

References

Reprints/ permissions

You can respond to this article at

Downloaded from
This article cites 0 articles, 0 of which you can access for free at: http://bjp.rcpsych.org/content/10/52/550.citation\#BIBL

To obtain reprints or permission to reproduce material from this paper, please write to permissions@rcpsych.ac.uk

/letters/submit/bjprcpsych;10/52/550

http://bjp.rcpsych.org/ on August 25, 2017

Published by The Royal College of Psychiatrists

To subscribe to The British Journal of Psychiatry go to: http://bjp.rcpsych.org/site/subscriptions/ 